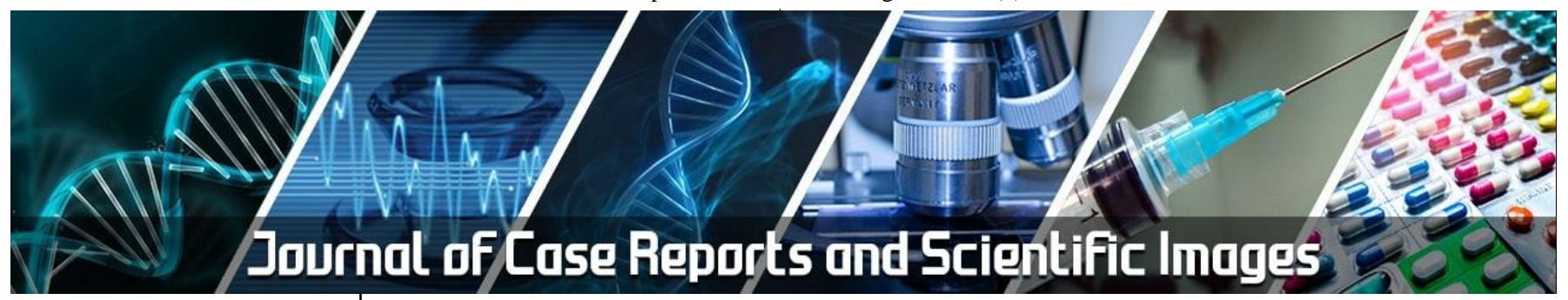

E-ISSN: 2708-0064 P-ISSN: 2708-0056 www.allcasereports.com JCRSI 2019; 1(1): 09-10 Received: 12-11-2018 Accepted: 15-12-2018

Divya Pandit

Department of Scientific, Maharani Lakshmi Ammanni College for Women,

Karnataka, India
Corresponding Author: Divya Pandit

Department of Scientific, Maharani Lakshmi Ammanni College for Women,

Karnataka, India

\section{Alopecia Areata in 12 years old female treated with Oral Azathioprine- A case report \& review}

\section{Divya Pandit}

DOI: https://doi.org/10.33545/27080056.2019.v1.i1a.5

\begin{abstract}
Alopecia Areata (AA) is an autoimmune condition that attacks the hair follicles. AA typically presents as smooth, sharply demarcated, round patches of hair loss without atrophy. We reported a case of Alopecia Areata (AA) in 12 years old female treated with oral azathioprine.
\end{abstract}

Keywords: Alopecia Areata, Autoimmune, Azathioprine.

\section{Introduction}

Alopecia Areata (AA) is an autoimmune condition that attacks the hair follicles, causing nonscarring hair loss. Some smaller studies indicate a slight female-to-male gender bias, but this may be due to higher female concern regarding hair loss and subsequent treatment ${ }^{[1]}$.

AA typically presents as smooth, sharply demarcated, round patches of hair loss without atrophy with "exclamation point hairs" observed on the periphery of the patches ${ }^{[2]}$. Special designations of the disease include alopecia universalis (AU) (total body hair loss), alopecia totalis (AT) (total scalp hair loss), or alopecia in an ophiasis pattern (band-like hair loss on the temporal and occipital scalp). Less common variants include the diffuse variant with widespread thinning of hair across the scalp or the reticular pattern with recurrent hair loss in one area and spontaneous hair regrowth in another. Ophiasis inversus causes band-like hair loss in the frontoparietotemporal area ${ }^{[3]}$.

Although asymptomatic, cosmetic unacceptability associated with the condition is distressing for the patients and frequently the reason for seeking medical consultation. Mostly, topical or locally intensive treatment modalities are resorted to for the treatment of segmental or patchy involvement in alopecia areata. Given the frequent recurrences associated with natural course of the disease, local treatment measures such as topical steroids and topical minoxidil do not offer therapeutic benefits of long-term remissions. Other immunosuppressive drugs (like oral azathioprine) in armamentarium are warranted nowadays to interrupt progression of the disease and achieve longer remissions ${ }^{[4]}$. We reported a case of Alopecia Areata (AA) in 12 years old female treated with oral azathioprine.

\section{Case Report}

A 12 year-old female patient reported to the department with patches of alopecia areata involving the scalp. History revealed that patient took so many medications for the same but in vain. Clinical examination revealed multiple patches of alopecia areata with partial areas of regrowth in the frontovertical area of the scalp.

Patient was given oral azathioprine in the dose of $25 \mathrm{mg}$ daily $(1 \mathrm{mg} / \mathrm{kg})$. She reported good hair growth by 6 weeks. On background of frequent episodes of recurrence reported in natural course of the disease, azathioprine was continued for 6 months, which resulted in remission. After 6 months, azathioprine was discontinued and the patient was maintained on topical minoxidil. The prognosis was good.

\section{Discussion}

Alopecia areata is a commonly encountered autoimmune condition which may present with wide spectrum of clinical presentations ranging from single or few smooth bald patches involving frontovertical or temporal areas to almost near-total or complete hair loss. 
Histologically, it reveals perifollicular T-cell colonization which prevents eruption of hair follicle to skin surface ${ }^{[5]}$. The exact pathophysiology of the disease is currently unknown. However, evidence suggests that AA is caused by an autoimmune reaction to the hair follicles due to both genetic and environmental factors. Genetic factors Observational studies show a high correlation (10\%-42\%) between AA and family history. Genome-wide association studies have identified numerous single-nucleotide polymorphisms (SNPs) associated with AA ${ }^{[6]}$. In a recent meta-analysis, human leukocyte antigen-DR (HLA-DR) on chromosome 6 appears to be the largest risk factor for AA. These HLA class II genes are highly linked to CD4+ and CD8+ T-cells, which are important effector cells in AA. In addition, this study implicated BCL2-like protein 11, also known as BIM, which helps to regulate autophagy in the disease pathogenesis. Genes encoding for natural killer cell receptor D ligands and downstream effectors of the JAK pathway also influence AA susceptibility ${ }^{[7]}$. We reported a case of Alopecia Areata (AA) in 12 years old female treated with oral azathioprine.

Environmental factors likely exacerbate or induce AA. Stress is an often-cited cause of AA, but the literature from human studies is inconclusive. However, in a mouse model, the activity of the central and peripheral hypothalamus pituitary adrenal axis was higher compared to normal mice. The elevated adrenocorticotropic hormone, corticosterone, and estradiol correlated to elevated pro-inflammatory cytokine levels in the skin, suggesting a potential role of psychological and physiological stressors to cause AA ${ }^{[8]}$. Other potential environmental stressors that may be implicated in AA include infections, vaccinations, hormone fluctuations, and diet, although their exact impact is unknown. In the mouse model, soy products have been associated with AA, and there are new studies emphasizing a correlation between AA and Vitamins A and D levels. It is likely that multiple environmental factors impact the disease course ${ }^{[9]}$.

Azathioprine is an antimetabolite drug having wide range of dermatological indications; of which predominantly listed are vitligo, autoimmune connective tissue disorders (systemic lupus erythematosus and dermatomyositis), photodermatoses, immunobullous disorders, refractory lepra reactions and vasculitides. Azathioprine and its analogues interfere with DNA synthesis by inhibition of enzymes of purine synthesis, thereby affecting proliferation of cytotoxic T-cells and also by suppression of cytokines release by helper T-cells which dampens the immune response ${ }^{[10]}$.

\section{Conclusion}

Authors found that Azathioprine is an antimetabolite drug having wide range of dermatological indications. Alopecia Areata (AA) is an autoimmune condition that can be well managed with Azathioprine.

\section{References}

1. Grossman AB, Noble AJ, Mamula P, Baldassano RN. Increased dosing requirements for 6-mercaptopurine and azathioprine in inflammatory bowel disease patients six years and younger. Inflamm Bowel Dis. 2008; 14:750-5.

2. Fuggle NR, Bragoli W, Mahto A, Glover M, Martinez AE, Kinsler VA et al. The adverse effect profile of oral azathioprine in pediatric atopic dermatitis, and recommendations for monitoring. J Am Acad Dermatol. 2015; 72:108-14.

3. Farshi S, Mansouri P, Safar F, Khiabanloo SR. Could azathioprine be considered as a therapeutic alternative in the treatment of alopecia areata? A pilot study. Int J Dermatol. 2010; 49:1188-93.

4. Vañó-Galván S, Hermosa-Gelbard Á, Sánchez-Neila N, Miguel-Gómez L, Saceda-Corralo D, Rodrigues-Barata $\mathrm{R}$ et al. Treatment of recalcitrant adult alopecia areata universalis with oral azathioprine. J Am Acad Dermatol 2016; 74:1007-8.

5. Relling MV, Gardner EE, Sandborn WJ, Schmiegelow $\mathrm{K}$, Pui $\mathrm{CH}$, Yee SW et al. Clinical pharmacogenetics implementation consortium guidelines for thiopurine methyltransferase genotype and thiopurine dosing. Clin Pharmacol Ther. 2011; 89:387-91.

6. Xing L, Dai Z, Jabbari A, Cerise JE, Higgins CA, Gong $\mathrm{W}$ et al. Alopecia areata is driven by cytotoxic $\mathrm{T}$ lymphocytes and is reversed by JAK inhibition. Nat Med. 2014; 20:1043-9.

7. Sundberg JP, Berndt A, Silva KA, Kennedy VE, Sundberg BA, Everts HB et al. Alopecia areata: Updates from the mouse perspective. J Investig Dermatol Symp Proc. 2013; 16:23-4.

8. McDonagh AJ, Tazi-Ahnini R. Epidemiology and genetics of alopecia areata. Clin Exp Dermatol. 2002; 27:405-9.

9. Villasante Fricke AC, Miteva M. Epidemiology and burden of alopecia areata: A systematic review. Clin Cosmet Investig Dermatol. 2015; 8:397- 403.

10. Lundin M, Chawa S, Sachdev A, Bhanusali D, Seiffert-Sinha K, Sinha AA, et al. Gender differences in alopecia areata. J Drugs Dermatol. 2014; 13:409- 13. 